\title{
Сорта картофеля для переработки
}

\author{
Cultivars of potatoes for processing
}

\author{
Сердеров В.К., Ханбабаев Т.Г., Сердерова Д.В.
}

\section{Аннотация}

Наряду с правильной организацией базой хранения, для эффективного использования картофеля большое значение имеет его переработка. Содержание сухого вещества - один из показателей качества пригодности сортов картофеля для его переработки. В статье обобщены результаты оценки урожайности сортов картофеля в климатических условиях высокогорья Республики Дагестан и содержания в клубнях сухого вещества как критерия пригодности сортов для переработки на картофелепродукты. Исследования проводили в опорном пункте «Курахский», МО «Курахский район» Республики Дагестан, расположенном на высоте 2000 - 2200 м над уровнем моря в 2017 и 2018 годах. Контроль - районированный в республике среднеранний сорт Волжанин. Схема посадки $70 \times 30$ см, повторность четырехкратная. Почвенный покров представлен горными каштановыми среднесуглинистыми почвами. Содержание гумуса - 2,91-3,01\%. Питательными веществами почвы обеспечены в средней степени: гидролизуемого азота - 2,2-3,5 мг, подвижного фосфора - 4-6 мг и обменного калия - 12,5-16,5 мг на 100 г. Погодные условия вегетационных периодов были благоприятные для возделывания картофеля. Средняя температура воздуха во время посадки (май) составила $11-12^{\circ} \mathrm{C}$, а во время вегетации летние месяцы - $14-16^{\circ} \mathrm{C}$. Опытные участки расположены опыты в засушливой зоне, так как выпадающие осадки во время вегетации (в среднем 60-80 мм в месяц) недостаточны для роста и развития картофеля. За время вегетации были проведены пять поливов по бороздам из расчета 50 л на м² (500 м³/га). По урожайности $(31,4-38,7$ т/га) в сравнении с контролем выделились сорта: Импала, Ирбитский, Жуковский ранний, Манифест, Матушка, Невский, Примобелла, Розара, Сильвана, Спиридон и Удача. По содержанию сухого вещества $(25,8-29,1 \%)$ в сравнении с контролем выделились сорта: Алена, Нарт, Гиоконда, Матушка, Росси, Вектор, Примобелла, Импало и Дезире.

Ключевые слова: картофель, климатические условия, урожайность, сухое вещество, переработка.

Для цитирования: Сердеров В.К., Ханбабаев Т.Г., Сердерова Д.В. Сорта картофеля для переработки // Картофель и овощи. 2020. №1. C. 24-26. https://doi.org/10.25630/PAV.2020.74.19.007

\author{
Serderov V.K., Khanbabaev T.G., Serderova D.V.
}

\section{Abstract}

Along with the correct organization of storage base, for the effective use of potatoes, its processing is of great importance. The dry matter content is one of the indicators of the quality of potato cultivars suitability for processing. The article summarizes the results of assessment of the yield of potato cultivars in the climatic conditions of the highlands of the Republic of Dagestan and the content of dry matter in tubers as a criterion for the suitability of cultivars for processing into potato products. The research was carried out in the reference point Kurakhsky, MO Kurakhsky district of the Republic of Dagestan, located at an altitude of 2000-2200 m above sea level in 2017 and 2018. Control-zoned in the Republic of mid-early cultivar Volzhanin. Planting scheme is $70 \times 30 \mathrm{~cm}$, repeat-four times. The soil is mountain brown medium loamy. Humus content is 2.91$3.01 \%$. Soil nutrients are provided to an average extent: hydrolyzed nitrogen 2.2-3.5 mg, mobile phosphorus 4-6 $\mathrm{mg}$ and exchange potassium $12.5-16.5 \mathrm{mg}$ per $100 \mathrm{~g}$. The weather conditions of the growing season were favourable for potato growing. The average air temperature during planting (May) was $11-12{ }^{\circ} \mathrm{C}$, and during the growing season the summer months was $14-16{ }^{\circ} \mathrm{C}$. Experimental plots are located in the arid zone, as precipitation during the growing season (on average $60-80 \mathrm{~mm}$ per month) is not sufficient for the growth and development of potatoes. During the growing season, five furrow irrigation was carried out at the rate of $50 \mathrm{I}$ per $\mathrm{m}^{2}(500$ $\left.\mathrm{m}^{3} / \mathrm{ha}\right)$. In terms of yield (31.4-38.7 t/ha) in comparison with the control, the following cultivars were distinguished: Impala, Irbitsky, Zhukovsky ranniy, Manifest, Matushka, Nevsky, Primobella, Rosara, Silvana, Spiridon and Udacha. According to the dry matter content (25.8-29.1\%) in comparison with the control, the following cultivars were distinguished: Alena, Nart, Gioconda, Matushka, Rossi, Vector, Primobella, Impala and Desire.

Key words: potato, climatic conditions, yield, dry matter, processing.

For citing: Serderov V.K., Khanbabaev T.G., Serderova D.V. Cultivars of potatoes for processing. Potato and Vegetables. 2020. No1. Pp. 24-26 (In Russ.). https://doi.org/10.25630/PAV.2020.74.19.007
П роизводство картофеля в России непрерывно развивается. В стране активно строятся новые и модернизируются уже существующие хранилища, год от года появляются новые участники рынка и расширяются площади посадок. В этих условиях переработка картофеля становится одним из способов повышения рентабельности отрасли.

Для перерабатывающего производства требуются специальные сорта картофеля. Один из сортовых показателей пригодности картофеля для переработки - содержание в клубнях сухого вещества [1, 3, 4]

Основные химические вещества, входящие в состав клубней картофе- ля, могут значительно изменяться в зависимости от сортовых особенностей, условий выращивания, климатических факторов. Клубни с содержанием сухого вещества выше 18-20\%, как правило, более чувствительны к поверхностным травмам, однако такие клубни легче развариваются при кулинарной обработке [1, 3, 4].

Кроме того, чипсы и картофель фри, приготовленные из картофеля с высоким содержанием сухого вещества, поглощают сравнительно мало масла или жира. Содержание сухого вещества влияет также на консистенцию готовых продуктов. Поэтому при производстве картофелепро- дуктов используют сорта с высоким содержанием сухого вещества (22\% и выше), которые дают большой выход сушеного продукта.

Сортовая политика в отрасли, а также сорта отечественной селекции составляют основу сортовых ресурсов в картофелеводстве России. Многие отечественные сорта картофеля выгодно отличаются от зарубежных аналогов, особенно по уровню их адаптивности к условиям выращивания, устойчивости к болезням, содержанию сухого вещества и крахмала (показателей, определяющих стабильные показатели вкусовых качеств клубней). 
Таблица 1. Урожайность сортов картофеля в условиях высокогорья Дагестана, 2017-2018 годы

\begin{tabular}{|c|c|c|c|c|c|c|}
\hline \multirow{3}{*}{ Сорт } & \multicolumn{4}{|c|}{ Урожайность } & \multirow{2}{*}{\multicolumn{2}{|c|}{ Среднее }} \\
\hline & \multicolumn{2}{|c|}{2017} & \multicolumn{2}{|c|}{2018} & & \\
\hline & т/га & $\%$ & т/га & $\%$ & т/га & $\%$ \\
\hline Волжанин (контроль) & 22,5 & 100 & 32,2 & 100 & 26,4 & 100 \\
\hline Алена & 20,6 & 92 & 25,6 & 78 & 22,8 & 86 \\
\hline Амур & 21,7 & 96 & 34,4 & 107 & 28,1 & 106 \\
\hline Вектор & 23,0 & 102 & 34,5 & 107 & 27,8 & 105 \\
\hline Гиоконда & 25,8 & 115 & 34,5 & 107 & 30,2 & 114 \\
\hline Дезире & 21,2 & 94 & 33,4 & 104 & 27,3 & 103 \\
\hline Импала & 31,7 & 141 & 37,4 & 116 & 34,6 & 131 \\
\hline Ирбитский & 27,2 & 121 & 37,6 & 117 & 32,3 & 122 \\
\hline Жуковский ранний & 29,0 & 129 & 33,9 & 105 & 31,5 & 119 \\
\hline Крепыш & 20,2 & 88 & 28,4 & 88 & 24,3 & 92 \\
\hline Манифест & 27,2 & 121 & 36,2 & 112 & 31,7 & 120 \\
\hline Матушка & 25,1 & 116 & 37,7 & 117 & 31,4 & 119 \\
\hline Нарт & 20,6 & 92 & 24,5 & 76 & 22,6 & 86 \\
\hline Невский & 26,6 & 118 & 37,9 & 118 & 32,3 & 122 \\
\hline Примобелла & 37,7 & 168 & 31,7 & 98 & 34,7 & 131 \\
\hline Ред Скарлетт & 25,8 & 115 & 25,8 & 80 & 25,8 & 98 \\
\hline Розара & 25,0 & 111 & 37,8 & 118 & 31,4 & 119 \\
\hline Росси & 25,1 & 111 & 25,3 & 77 & 25,2 & 95 \\
\hline Сильвана & 37,4 & 166 & 37,1 & 115 & 37,3 & 141 \\
\hline Спиридон & 31,4 & 140 & 39,9 & 124 & 35,6 & 135 \\
\hline Удача & 37,6 & 168 & 39,9 & 124 & 38,7 & 147 \\
\hline $\mathrm{HCP}_{05}$ & 1,43 & & 3,1 & & & \\
\hline
\end{tabular}

Цель исследования: оценить урожайность и содержание сухого вещества в клубнях картофеля сортов для промышленной переработки, выращенных в условиях высокогорья Республики Дагестан.

Условия, материалы и методы исследований

Исследования проводили в опорном пункте «Курахский», МО «Курахский район» Республики Дагестан, расположенном на высоте 2000 - 2200 м над уровнем моря в 2017 и 2018 годах.

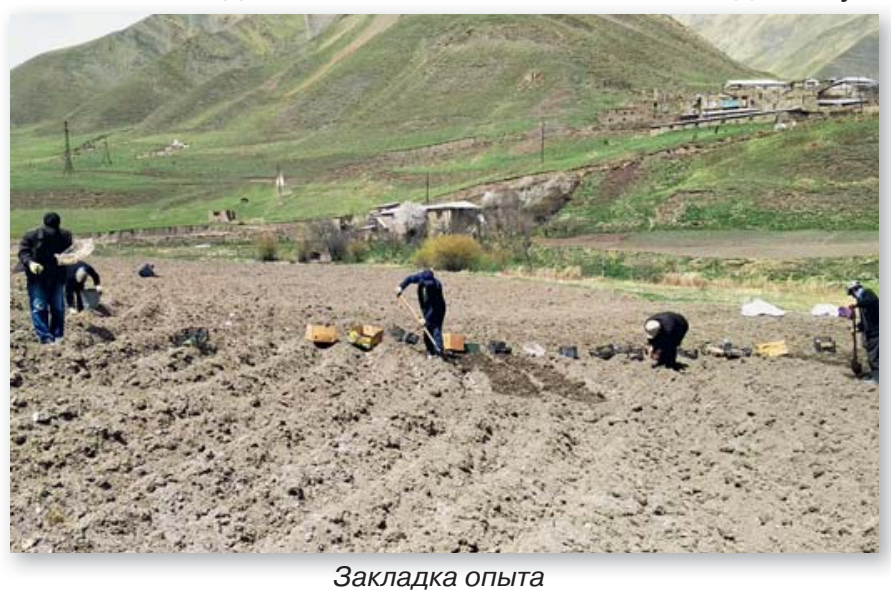

словия вегетационных периодов были благоприятные для возделывания картофеля. Средняя температура воздуха во время посадки (май) составила 11-12 ${ }^{\circ} \mathrm{C}$, а во время вегетации летние месяцы - 14$16^{\circ} \mathrm{C}$.

Территория, где проводили опыты, относится к засушливой зоне, так как вы-

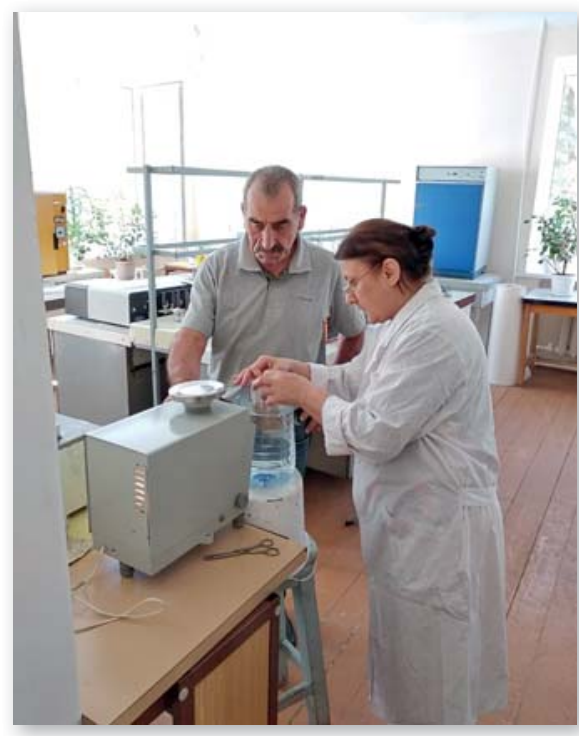

Определение сухого вещества весовым методом

падающие осадки во время вегетации (в среднем 60-80 мм в месяц) недостаточны для роста и развития картофеля.

За время вегетации были проведены пять поливов по бороздам из расчета 50 л на м² (500 м³/га).

Исследования проводили по стандартным методикам (Методические указания по оценке сортов картофеля на пригодность к переработке и хранению, Методика определения крахмала и сухого вещества весовым методом) [2, 5, 6].

\section{Результаты исследований}

Большое значение в картофелеводстве имеет внедрение в производство перспективных высокоурожайных сортов, приспособленных к местным природно-климатическим условиям среды возделывания, так как от полученной урожайности зависит эффективность отрасли и себестоимость выращенной продукции.

Для промышленной переработки картофеля необходимы зрелые клубни сортов разных сроков созревания (чтобы обеспечить производство в течение всего года) с содержанием сухого вещества от $22 \%$ и более.

Полученные по результатам исследований данные приведены в таблицах 1 и 2.

Несмотря на то, что условия возделывания у всех сортов были одинаковыми, в среднем за два года урожайность у контроля (сорт Волжанин) - 26,4 т/га, лучшие показатели были у сортов: Удача - 38,7 т/га или 147\% к контролю, Сильвана - 37,3 т/га (141\%) и Спиридон - 35,6 т/га 
Таблица 2. Содержание сухого вещества в клубнях картофеля сортов, выращенных в условиях высокогорья Республики Дагестан, 2017-2018 годы

\begin{tabular}{|c|c|c|c|c|}
\hline \multirow{2}{*}{ Сорт } & \multirow{2}{*}{ До посадки, \% } & \multicolumn{3}{|c|}{ После уборки, \% } \\
\hline & & 2017 & 2018 & Среднее \\
\hline Волжанин (контроль) & 20,2 & 24,2 & 24,2 & 24,2 \\
\hline Алена & 21,8 & 25,4 & 26,2 & 25,8 \\
\hline Амур & 19,7 & 24,9 & 25,0 & 24,9 \\
\hline Вектор & 24,2 & 27,9 & 27,5 & 27,7 \\
\hline Гиоконда & 23,2 & 26,1 & 27,5 & 26,8 \\
\hline Дезире & 25,3 & 28,8 & 29,5 & 29,1 \\
\hline Импала & 18,1 & 24,2 & 24,5 & 24,3 \\
\hline Ирбитский & 20,6 & 24,8 & 24,5 & 24,6 \\
\hline Жуковский ранний & 16,7 & 20,7 & 21,0 & 20,8 \\
\hline Крепыш & 15,9 & 19,7 & 20,2 & 20,0 \\
\hline Манифест & 19,7 & 24,0 & 24,0 & 24,0 \\
\hline Матушка & 22,7 & 26,6 & 27,0 & 26,8 \\
\hline Нарт & 21,3 & 25,5 & 25,5 & 25,5 \\
\hline Невский & 19,7 & 23,7 & 24,0 & 23,9 \\
\hline Примобелла & 23,7 & 27,9 & 27,9 & 27,9 \\
\hline Ред Скарлет & 19,9 & 23,5 & 24,2 & 23,8 \\
\hline Розара & 20,8 & 24,8 & 25,0 & 24,9 \\
\hline Росси & 23,2 & 27,7 & 27,5 & 27,5 \\
\hline Сильвана & 20,6 & 24,0 & 24,5 & 24,3 \\
\hline Спиридон & 20,6 & 24,0 & 24,5 & 24,3 \\
\hline Удача & 18,8 & 22,2 & 23,0 & 22,6 \\
\hline $\mathrm{HCP}_{05}$ & 2,1 & 2,3 & 2,6 & \\
\hline
\end{tabular}

\section{Библиографический список}

1.Анисимов Б.В. Сорта картофеля, возделываемые в России: Справочное издание / Б.В. Анисимов, С.Н. Еланский, В.Н. Зейрук и др. М.: Агроспас, 2013. 144 с.

2.Ганзин Г.А., Макунина Н.П. Методика определения крахмала и сухого вещества весовым методом. М., 1977. 76 с.

3.Коршунов А.В., Филиппова Г.И., Гаитова Н.А., Митюшкин А.В., Кутовенко Л.Н. Управление содержанием крахмала в картофеле // Аграрный вестник Урала. 2011. № 2 (81). С. 47-50.

4.Маханько В.Л., Козлова Л.Н., Незаконова О.Б. Сортовые особенности картофеля и их использование в кулинарии и перерабатывающей промышленности //Земледелие и защита растений. 2013. № 3. С.62-64.

5.Методика исследований по культуре картофеля НИИКХ. М.: Агропромиздат. 1967.114 с.

6.Методические указания по оценке сортов картофеля на пригодность к переработке и хранению / К.А. Пшеченков, О.Н. Давыденкова, В.И. Седова, С.В. Мальцев. М., 2008. 122 с.
(135\%). Преимущество одного сорта над другим по урожайности обусловлена разной степенью адаптивности у разных сортов к выращиванию в условиях высокогорья.

В России картофель служит основным сырьем для получения крахмала. На крахмал приходится более $75 \%$ состава сухого вещества, содержащегося в клубнях. Один из важных биохимических показателей картофеля - содержание в клубнях сухого вещества, поскольку именно от этого показателя зависит и качество при переработке.

По результатам наших исследований (табл. 2), высоким содержанием сухого вещества по сравнению с контролем выделились сорта: Алена, Нарт, Гиоконда, Матушка, Росси, Вектор, Примобелла, Импало и Дезире.

\section{Выводы}

По урожайности $(31,4-38,7$ т/ га) в сравнении с контролем выделились сорта: Импала, Ирбитский, Жуковский ранний, Манифест, Матушка, Невский, Примобелла, Розара, Сильвана, Спиридон и Удача.

Высоким содержанием сухого вещества $(25,8$ - 29,1\%) по сравнению с контролем выделились сорта: Алена, Нарт, Гиоконда, Матушка, Росси, Вектор, Примобелла, Импало и Дезире.

\section{References}

1.Anisimov B.V., Elanskij S.N., Zejruk B.N. et al. Cultivars of potato, grown in Russia. Moscow. Agrospas. 2013. 144 p. (In Russ.).

2.Ganzin G.A., Makunina N.P. Methodology of determination of starch and dry matter by a gravimetric method. Moscow. 1977. 76 p. (In Russ.).

3.Korchunov A.V., Filippova G.I., Gaitova N.A., Mitiushkin A.V., Kutovenko L.N. Management by maintenance of starch in the potato. Agrarian herald of Ural. 2011. No 2 (81). Pp. 47-50. (In Russ.).

4.Makhan'ko V.L., Kozlov L.N., Nezakonova O.B. Cultivars features of potato and their use in cookery and processing industry. Agriculture and plant protection. 2013. No3. Pp. 62-64. (In Russ.).

5.Methodology of researches on potato crop of NIIKKH. Moscow. Agropromizdat. 1967. 114 p. (In Russ.).

6.Pshechenkov K.A., Davydenkova O.N., Sedova V.I., Maltsev S.V. Methodical pointing as evaluated by the sorts of potato on fitness to processing and storage. Moscow. 2008. 122 p. (In Russ.).

\section{Об авторах}

Сердеров Валерик Каибханович, канд. с.-х. наук, доцент, зав. лабораторией картофелеводства и овощеводства, ФГБНУ «Федеральный аграрный научный центр республики Дагестан». Тел.: +7 (928) 524-22-13. E-mail: serderov55@mail.ru

Ханбабаев Темирлан Гайдарбекович, канд. экон. наук, доцент, зав. отделом региональной экономики АПК, ФГБНУ «Федеральный аграрный научный центр республики Дагестан». Тел.: +7 (928) 581-56-60. E-mail: econ.dagniish@mail.ru

Сердерова Динара Велибековна, м.н.с. лаборатории картофелеводства и овощеводства, ФГБНУ «Федеральный аграрный научный центр республики Дагестан». Тел. +7 (919) 441-21-83. E-mail: niva1956@mail.ru

\section{Author details}

Serderov V.K., Cand. Sci. (Agr.), associate professor, head of laboratory of potato and vegetable growing, Federal Agrarian Scientific Centre of Republic of Dagestan. Phone: +7 (928) 524-2213. E-mail: serderov55@mail.ru

Khanbabaev T.G. Cand. Sci. (Econ.), associate professor, by the department of regional economy of agrarian industrial complex, Federal Agrarian Scientific Centre of Republic of Dagestan. Phone: +7 (928) 581-56-60. E-mail: econ.dagniish@mail.ru

Serderova D.V. junior research fellow, laboratory of potato and vegetable-growing, Federal Agrarian Scientific Centre of Republic of Dagestan. Phone: +7 (919) 441-21-83. E-mail: niva1956@mail.ru 